\title{
The relationship of peripheral trauma and pain to dystonia
}

\author{
GD SCHOTT
}

From The National Hospital for Nervous Diseases, London, UK

SUMMARY Four patients are described who sustained comparatively minor peripheral injury, the affected area soon becoming the site of segmental dystonia. The movement disorder developed as the symptoms from the injury subsided, and except for the recent trauma, no cause for the dystonia was apparent; litigation was not an issue for any patient. It is suggested that on rare occasions peripheral trauma results in the development of dystonia. Since injury never involved the head, the role of the spinal dopaminergic system and the relevance of pain from the injury are discussed in considering possible underlying mechanisms.

Many patients with dystonia have no obvious cause for their involuntary movements, although in a number of instances an underlying process can be identified. Such processes include exposure to drugs and especially those with psychotropic properties, birth anoxia, Wilson's disease, encephalitis and cerebral infarctions and trauma. ${ }^{1}$ More recently it has been appreciated that cerebral insults from a variety of causes can be associated with dystonia that occurs after an interval of many years. ${ }^{2}$ The present report draws attention to the unexpected development of dystonia occurring after comparatively minor peripheral trauma, when cerebral damage could be excluded with certainty.

\section{Case reports}

Case 1 This 50-year-old man slipped on the ice 18 months previously, falling on to his right hip and lower trunk. He had considerable local pain and bruising which gradually resolved over some weeks; there was no fracture. Coinciding with the resolution, he developed difficulty with walking, with involuntary twisting movements of the lumbar spine and pelvis. Over a period of months, the involuntary movements increased; he found that whenever he stood or walked, his trunk would twist and writhe, sometimes side to side, sometimes forwards and backwards and

Address for reprint requests: Dr GD Schott, The National Hospital for Nervous Diseases, Queen Square, London, WC1N 3BG, UK.

Received 4 January 1984 and in revised form 6 November 1984. Accepted 5 January 1985 often with a complex rotational component. At one stage he could run but not walk without symptoms; sitting or leaning against an object caused no problems. These disabilities have continued to worsen slightly. The illness led elsewhere to investigations of an orthopaedic nature, with myelography and subsequent laminectomy at $\mathrm{L} 4 / 5$ for suspected disc herniation. No compressive lesion was found and the operation did not influence his symptoms. Serum copper and caeruloplasmin levels were normal. Examination revealed no abnormality at rest. On standing or walking, however, he immediately produced irregular twisting movements of a sinuous, writhing quality, sometimes with a jerk-like component, that affected the pelvis and trunk. Attempts at treatment with benzodiazepine and anticholinergic medication have been unsuccessful.

Case 2 Initially referred for an orthopaedic opinion, this 56 -year-old labourer had twisted his back loading 56 pounds $(25 \mathrm{~kg})$ cement on to a lorry two years previously. He immediately developed a severe burning, aching pain in the left lower lumber region in the paraspinal area with some spread to the left buttock. The pain gradually subsided over some weeks although he has had occasional minor recurrences since. Four months after the injury, he became aware that his walking was abnormal: he would make a curious rotating, rolling movement of the lower trunk and the left leg would often be thrown forward and his pelvis would twist. He had never experienced any weakness. To his own surprise, he had found walking backwards considerably easier and he had recently climbed 2000 feet $(600 \mathrm{~m})$ up Mount Snowdon mostly backwards. There was no relationship between the episodes of pain and the abnormal trunk and leg movements, the latter having become a persistent feature which he had learnt to live with. Examination was unremarkable when he was at rest, but on walking there was a bizarre rotational tilting and 
twisting of the pelvis to the left with circumduction and inversion of the left leg which were completely abolished when he walked backwards. There was no pain at the time of examination. Investigations revealed widespread degenerative changes on radiographs of the spine.

Case 3 Two years ago this 60-year-old groundsman pulled the cord of the starter motor of his mowing machine. He immediately developed acute pain in the right upper arm and felt something tear around the shoulder. The acute pain settled over three weeks but he developed weakness and instability on movement of the right shoulder. Examination some weeks later revealed weakness and considerable wasting of the spinati unaccompanied by sensory loss or reflex changes; radiographs showed no abnormality of the shoulder joint, and a diagnosis of a traumatic suprascapular nerve lesion was made. Exploration of the nerve was considered, but regular follow-up indicated slow spontaneous recovery, and after about a year, the weakness and wasting had almost fully recovered. Six months after the injury, and whilst recovery was occurring, the present symptoms began. The right shoulder girdle and upper arm tended to make spontaneous forward, thrusting movements. Initially this occurred occasionally, but fairly soon the involuntary movements became more obtrusive: they were present much of the time, tended to be more prominent with activity such as writing, driving and picking up objects, and there was more widespread involvement. The arm and hand would writhe and abduct, and at times his fingers would make cramp-like movements. There was no weakness, sensory impairment or pain. Examination of this right-handed man revealed minor asymptomatic torticollis and retrocollis and marked writhing, dystonic movements of the right shoulder, arm, hand and fingers. He wrote awkwardly, with his arm tending to externally rotate, and he gripped the pen forcefully. When walking, his right upper arm often supinated. There was no tremor or alteration of tone, and the only other abnormal sign was slight weakness of the spinati. Investigations failed to reveal any underlying cause, and he gained some modest benefit from benzhexol, 2 mg thrice daily.

Case 4 Three years ago, this 30-year-old right-handed Ugandan Asian secretary closed the bonnet (hood) of her car with some force. She suddenly developed severe pain at the base of the right thumb, there was a brief stab of pain up the inner aspect of the arm, and shortly after, considerable swelling developed in the painful area of the hand. She was thought to have sustained a forced abductionextension injury to the thumb. Because of the continuing pain and swelling, she was sent to a local hospital where radiographs revealed no abnormality. Gradually over some months the pain and swelling resolved, although at times she complained of some residual ache around the thumb. At the time her symptoms were improving, she was aware of some new difficulties that predominantly affected writing. The right hand tended to deviate involuntarily laterally and she had to grip the pen tightly. Later more widespread involuntary movements occurred on writing: the fingers would bunch up and sometimes fan, the elbow and shoulder would abduct, and at times a little tremor of the arm developed. In addition, other activities involving the right upper limb would induce these movements, for instance using cutlery, doing up buttons and gripping the car steer- ing wheel. About a year ago, she changed to writing with the left hand, and had to press the right arm against her side to prevent it wandering. Pain was no longer a problem, other than aching of the right forearm muscles when she tried to write. Examination revealed no abnormality at rest. On writing and other activities requiring dexterity with the right hand, however, her arm and hand produced dystonic movements as she described, and the arm tended to move away from her side. Writhing movements were also apparent on the finger-nose test, but there was no ataxia. Arm movements were normal when she walked, as was her gait. Investigations revealed no evidence of any peripheral nerve lesion in the arm, radiographs of the hands and wrists remained normal, but she declined further investigations or treatment.

\section{Discussion}

These four patients each sustained definite although comparatively minor injury to a part of the body which very soon became affected by dystonic involuntary movements. The cases represent examples of segmental dystonia, Cases 1 and 2 being truncal dystonia or axial dystonia musculorum deformans, and segmental dystonia affecting the upper limb was present in Case 3 and writer's cramp in Case 4. Some spread of the abnormal movements occurred so that adjacent areas became involved, but the painful, injured part was the initial "focus" of the dystonia. In no patient was there any known family history of movement disorder or of consanguinity, and no patient was of Jewish extraction. Previous drug exposure had not occurred, litigation was not an issue for any patient, and there was no obvious malingering or other source of gain as a consequence of either the injury or the dystonia. It is of interest that the patients were all referred from orthopaedic or rheumatology departments being suspected of having a peripheral nerve or other local cause. ${ }^{3}$ They were seen over an eighteen-month period, suggesting that such cases may not be uncommon, and enquiry concerning previous trauma may be appropriate in patients with dystonia.

The close temporal relationship between injury and the development of subsequent dystonia is noteworthy, and indeed the symptoms of the former virtually merged into those of the latter. Also noteworthy is the topographical relationship between the site of injury and that of the involuntary movement. While patients tend to ascribe their disability to a particular preceding event, the relationship between these patients' trauma and subsequent dystonia seems very unlikely to be fortuitous, especially recalling the rarity of the dystonias which, in the case of dystonia musculorum deformans, has an estimated prevalence in the USA of three per 
million. ${ }^{4}$ It is suggested, therefore, that in the present patients a causal association existed between peripheral injury and the development of dystonia.

There are a number of central nervous system disorders in which on occasions peripheral trauma appears to act as an initiating factor, although a direct link is often only tenuous. Disorders affecting the motor system included motor neuron disease ${ }^{5}$ and Parkinson's disease ${ }^{6}$ in which trauma as an aetiological factor is very uncommon; disorders involving the sensory system include the not infrequent development of "central" pain states that can follow peripheral trauma, as illustrated by patients with phantom pain and those who develop spreading and presumably central pain after peripheral injury, for instance following dental extraction or peripheral damage to a limb. There also appear to be instances where trauma may initiate various combinations of central motor and sensory disturbances, as for instance in multiple sclerosis, ${ }^{7}$ the rare syndrome of "painful legs and moving toes", ${ }^{8}$ and muscle spasms associated with Sudeck's atrophy."

Peripheral trauma giving rise to dystonia has rarely been alluded to before. Gowers mentioned the case of a naval officer who sprained his thumb and who subsequently developed writer's cramp. ${ }^{10}$ Kinnier Wilson, commenting on the aetiology of occupational cramps, mentioned that "injury, too, such as sprain, has been known to bring on the trouble." $" 1$ The comparatively high frequency of local inflammatory and (non-traumatic) peripheral nerve lesions in musicians with dystonic phenomena has been noted recently. ${ }^{12}$ Of interest is the observation that previous trauma precedes the onset of spasmodic torticollis in up to $10 \%$ of cases; ${ }^{13}$ in view of the area involved, however, it would be difficult or impossible to exclude direct damage to the central nervous system or root entry zones. There may also be iatrogenic causes: tooth extraction in elderly patients seems to be an underlying factor in the development many years later of orofacial dyskinesias, especially when patients lack dentures..$^{14}$

The mechanisms by which dystonia could occur following peripheral trauma are as obscure as those contributing to idiopathic and secondary dystonias. Since lesions of peripheral sensory pathways cause far reaching changes proximal to the site of damage and also centrally, ${ }^{15}$ similar processes could occur in the motor system. Such central changes following peripheral lesions of the facial nerve in man have been suggested, ${ }^{16}$ and that the dystonia in the present patients occurred in or near the region of the injured part raises the possibility of neurological dysfunction at segmental level. With the realisation that a diencephalospinal dopaminergic system exists in animals and probably humans, ${ }^{17}$ this system with cell bodies at hypothalamic and thalamic level and providing dopaminergic innervation of the spinal cord could perhaps be implicated in focal dystonic disturbances. Analogous with spinal or segmental myoclonus, "spinal dystonia" could explain the segmental nature of the involuntary movements of the present patients, and obviate the need to postulate ascending neuronal dysfunction with termination at basal ganglia level.

Finally, the role of pain needs consideration. Obviously trauma very frequently results in pain; this occurred in the present patients and has also been noted in patients with, for instance, traumaassociated multiple sclerosis. It could be that it is the central sensory mechanisms subserving pain that represent the triggering factor, especially since peripheral trauma may be followed by involvement of many systems as demonstrated by the motor, sensory, autonomic and trophic changes seen in causalgia. Perhaps involuntary movements should be added to this list, particularly since spinal dopaminergic neurons may be involved in pain modulation and autonomic and motor responses. ${ }^{17}$ Whilst it is very rare for pain and for trauma to be followed by involuntary movements, it is suggested that on occasions, peripheral injury may be a specific factor in the subsequent development of dystonia.

I am very grateful to $\mathrm{Dr} A \mathrm{AJ}$ Lees and Professor CD Marsden, FRS for valuable discussion.

\section{References}

' Zeman W, Whitlock CC. Symptomatic dystonias. In: Vinken PJ, Bruyn GW, eds. Handbook of Clinical Neurology, Vol 6. Amsterdam: North-Holland Publishing Company, 1968:544-66.

${ }^{2}$ Burke RE, Fahn S, Gold AP. Delayed-onset dystonia in patients with "static" encephalopathy. J Neurol Neurosurg Psychiatry 1980;43:789-97.

${ }^{3}$ Schott GD. The idiopathic dystonias: a note on their orthopaedic presentation. J Bone Joint Surg 1983; 65B:51-4.

${ }^{4}$ Eldridge R. The torsion dystonias: literature review and genetic and clinical studies. Neurology (Minneap) 1970; 20 (Part 2): 1-78.

${ }^{5}$ Kondo K, Tsubaki T. Case-control studies of motor neuron disease. Association with mechanical injuries. Arch Neurol 1981;38:220-6.

- Walker GF. Parkinsonism following peripheral trauma. Br Med J 1937;2:65.

${ }^{7}$ Miller H. Trauma and multiple sclerosis. Lancet 1964; 1:848-50.

${ }^{8}$ Schott GD. "Painful legs and moving toes": the role of trauma. J Neurol Neurosurg Psychiatry 1981; 44:344-6.

${ }^{9}$ Marsden CD, Obeso JA, Traub MM, Rothwell JC, Kranz H, La Cruz F. Muscle spasms associated with 
Sudeck's atrophy after injury. Br Med J 1984;288: 173-6.

${ }^{10}$ Gowers WR. A Manual of Diseases of the Nervous System, Vol 2. London: Churchill, 1888:659.

"Wilson SAK. Neurology, Vol 3, 2nd edition. London: Butterworth, 1955:1966.

${ }^{12}$ Hochberg FH, Leffert RD, Heller MD, Merriman L. Hand difficulties among musicians. JAMA 1983; 249: $1869-72$.

${ }^{13}$ Sheehy MP, Marsden CD. Trauma and pain in spasmodic torticollis. Lancet 1980;1:777-8.

${ }^{14}$ Koller WC. Edentulous orodyskinesia. Ann Neurol 1983;13:97-9.
15 Wall PD. Alterations in the central nervous system after deafferentation: connectivity control. In: Bonica JJ, Lindblom U, Iggo A, eds. Advances in Pain Research and Therapy, Vol 5. New York: Raven Press, 1983:677-89.

${ }^{16}$ Bratslavsky M, vander Eecken $H$. Altered synaptic organization in facial nucleus following facial nerve regeneration: an electrophysiological study in man. Ann Neurol 1977;2:71-3.

${ }^{17}$ Lindvall O, Björklund A, Skagerberg G. Dopaminecontaining neurons in the spinal cord: anatomy and some functional aspects. Ann Neurol 1983;14:25560 . 